\title{
Direct Preparation of Hydrogen and Carbon Nanotubes by Microwave Plasma Decomposition of Methane over Fe/Si Activated by Biased Hydrogen Plasma
}

\author{
Katsuya Konno $^{1,2}$, Kaoru Onoe ${ }^{2}$, Yasuyuki Takiguchi ${ }^{2}$, Tatsuaki Yamaguchi ${ }^{2 *}$ \\ ${ }^{1}$ Hitachi Automotive Systems Ltd., Automotive Systems R\&D Laboratory, Kawasaki, Japan \\ ${ }^{2}$ Department of Life and Environmental Sciences, Faculty of Engineering, Chiba Institute of Technology, Chiba, Japan \\ Email: "tatsuaki.yamaguchi@it-chiba.ac.jp
}

Received September 23, 2012; revised October 30, 2012; accepted November 12, 2012

\begin{abstract}
Methane was decomposed to hydrogen and carbon nanotubes (CNTs) by microwave plasma, using Fe/Si catalyst activated by biased $(-150 \mathrm{~V})$ hydrogen plasma for various treatment times. Upon exposure to biased hydrogen plasma, the catalyst surface becomes lumpy within $1 \mathrm{~min}$, coheres between 5 and $10 \mathrm{~min}$ and forms particles after $20 \mathrm{~min}$. The methane conversion increased up to $93 \%$ over the treatment time of $5 \mathrm{~min}$. The hydrogen yield showed as similar tendency as the methane conversion and kept $83 \%$ at treatment time of $5 \mathrm{~min}$. The treatment time up to 1 min increased the amount of deposited carbon, and after treatment time of $5 \mathrm{~min}$ it dropped; then again after treatment time of $20 \mathrm{~min}$, it increased to reach a maximum value of $22 \mathrm{~g}_{\mathrm{c}} / \mathrm{g}_{\mathrm{cat}}$. Deposited carbon was found to be consisted of carbon nanotubes. It grew vertically on the catalyst surface and reached a maximum length of $30.7 \mathrm{~nm}$ after treatment time of $10 \mathrm{~min}$. Multiple types of CNTs were present, and the CNT diameters decreased with increasing plasma treatment time.
\end{abstract}

Keywords: Hydrogen; Methane Decomposition; Carbon Nanotubes; Microwave Plasma; Methane; $\mathrm{H}_{2}$ Plasma Treatment

\section{Introduction}

Hydrogen production from methane is conventionally preformed with following reactions by steam reforming or partial oxidation.

$$
\begin{aligned}
& \mathrm{CH}_{4}+\mathrm{H}_{2} \mathrm{O} \rightarrow \mathrm{CO}+3 \mathrm{H}_{2} \\
& \mathrm{CH}_{4}+1 / 2 \mathrm{O}_{2} \rightarrow \mathrm{CO}+2 \mathrm{H}_{2}
\end{aligned}
$$

Although the reactions produce $\mathrm{CO}$, it is usually removed by the oxidation to $\mathrm{CO}_{2}$ for the purpose of hydrogen production. However, this is an inconvenient fact to emit large quantities of $\mathrm{CO}_{2}$, greenhouse effect gas. Therefore, the following reaction proceeded by thermal cracking of methane is expected.

$$
\mathrm{CH}_{4} \rightarrow 2 \mathrm{H}_{2}+\mathrm{C}
$$

According to the thermodynamics Equation (3) can proceed in the range of temperature from $1000^{\circ} \mathrm{C}$ to $2000^{\circ} \mathrm{C}$ [1]. This temperature is higher than that of general chemical engineering processes. Therefore Ni [2-7], Fe $[8,9]$ and Co [10] based catalyst has been used to decompose methane at lower temperature. Venugopal et al. obtained the methane conversion of $32 \%$, decomposing

"Corresponding author. methane at $600^{\circ} \mathrm{C}$ under $30 \mathrm{wt} \% \mathrm{Ni} / \mathrm{SiO}_{2}$ [4]. Suelves et al. obtained the methane conversion of $67 \%$ and hydrogen concentration of $80 \%$ at $700^{\circ} \mathrm{C}$ under Ni-based catalyst [6]. Shah et al. obtained the hydrogen yield of 80 $90 \mathrm{vol} \%$, decomposing methane at $700^{\circ} \mathrm{C}-800^{\circ} \mathrm{C}$ under Fe-M ( $\mathrm{M}=\mathrm{Pd}$, Mo and Ni) catalyst supported on alumina [10]. In these studies, although the hydrogen concentration is high $(80 \%-90 \%)$, the methane conversion is not so high. Onoe et al. reported that the high selectivities of acetylene and hydrogen are performed with a high $\mathrm{CH}_{4}$ conversion by the microwave plasma technique with following reaction [11].

$$
\mathrm{CH}_{4} \rightarrow 1 / \mathrm{C}_{2} \mathrm{H}_{2} 2+3 / 2 \mathrm{H}_{2}
$$

To obtain higher yield of hydrogen from methane decomposed by microwave plasma, further decomposition of acetylene is necessary. Therefore, the microwave plasma is used together with a catalyst for preceding the following reaction, expecting the resulting carbon become carbon nanotubes

$$
\mathrm{C}_{2} \mathrm{H}_{2} \rightarrow \mathrm{H}_{2}+2 \mathrm{C}
$$

In this study, we investigated that the effect of catalyst treatment time of biased hydrogen plasma on microwave 
plasma decomposition of methane.

\section{Experimental}

\subsection{Experimental Apparatus}

A low-pressure flow type reaction microwave remote plasma apparatus (ULVAC Inc., CN-CVD-100R) was used, which is shown in Figure 1. The apparatus consists of a gas supply unit, a microwave generator, a plasma generator, a chamber and a low pressure unit. Microwaves are generated by an air-cooled magnetron and then introduced into a plasma furnace through a horizontally placed waveguide (height $50 \mathrm{~mm}$, width $96 \mathrm{~mm}$ ) that complied with the appropriate specifications. Reflected waves were reduced using a three-stub tuner and removed by an isolator.

\subsection{Experimental Procedure}

Market-grade methane and hydrogen were used. A silicon wafer $(10 \mathrm{~mm} \times 10 \mathrm{~mm})$ was used as a substrate, onto which Fe was deposited using RF sputtering at $20 \mathrm{~W}$. The thickness of the deposited Fe was $10 \mathrm{~nm}$. The catalyst was set in the chamber at the position of $650 \mathrm{~mm}$ from the wave-guide. The hydrogen plasma treatment involved supplying the catalyst at a flow rate of $80 \mathrm{ml} / \mathrm{min}$ and an initial pressure of $180 \mathrm{~Pa}$ and exposing it to hydrogen plasma generated by a $500 \mathrm{~W}$ microwave under a bias of $-150 \mathrm{~V}$ at $550^{\circ} \mathrm{C}$ from $1 \mathrm{~min}$ to $30 \mathrm{~min}$. The mixed gas of 1:4 molar ratios of methane and hydrogen was introduced into the reactor at a flow rate of 100 $\mathrm{ml} / \mathrm{min}$ and an initial pressure of $254 \mathrm{~Pa}$. This gas was exposed to a $500 \mathrm{~W}$ microwave field for $30 \mathrm{~min}$, and then the catalyst was heated under non-biased conditions to $600^{\circ} \mathrm{C}$.

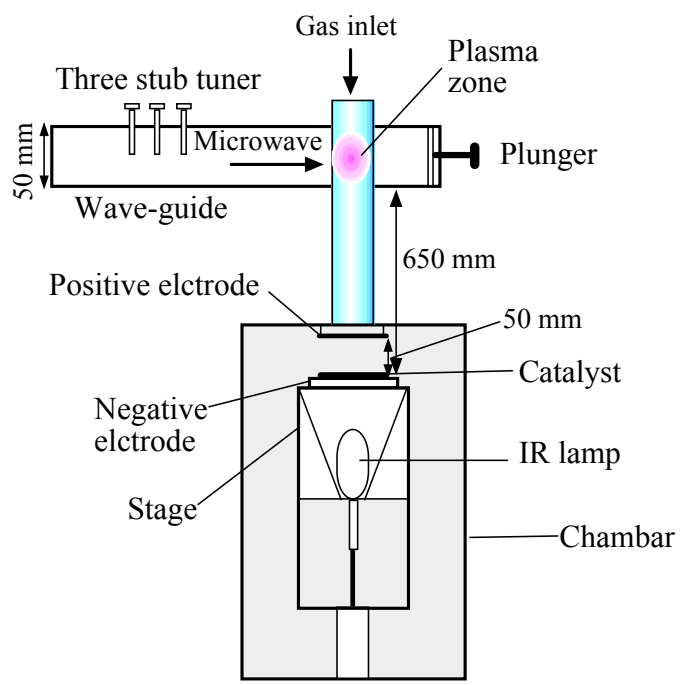

Figure 1. Experimental apparatus for the microwave plasma.

\subsection{Calculation of Methane Conversion, Hydrogen Yield, Carbon Yield and Molar Fraction of Output Gas}

Gaseous products obtained at $30 \mathrm{~min}$ of microwave reaction time was analyzed by gas chromatography. From an analysis of gas chromatography, carbon distribution (CD) of output gases and deposited carbon was calculated. Also hydrogen distribution (HD) of hydrocarbon and $\mathrm{H}_{2}$ obtained from $\mathrm{CH}_{4}$ was calculated. Methane conversion $\left(\mathrm{X}_{\mathrm{CH}_{4}}\right)$ was the total value of the $\mathrm{CD}$ of hydrocarbon without $\mathrm{CH}_{4}$ and deposited carbon. The Carbon yield was calculated from the amount of deposited carbon divided by the weight of $\mathrm{Fe} / \mathrm{Si}$ catalyst.

\subsection{Analysis of Products}

Output gases were analyzed using gas chromatograph equipped with a TCD detector (SHIMADZU GC-14B, column: SHINCARBON T). The characteristic of the catalyst was analyzed using scanning electron microscopy (SEM; JSM-6300, JEOL Ltd.). The CNTs were analyzed using SEM, transmission electron microscopy (TEM; H-9000, Hitachi High-Technologies Corporation).

\section{Results and Discussion}

\subsection{SEM Image of the Fe Catalyst Surface Activated by Biased $\mathrm{H}_{2}$ Plasma for Various Treatment Time}

Figure 2 shows SEM images of surface conditions of $\mathrm{Fe}$ activated by biased hydrogen plasma for various treatment times. The catalyst surface becomes rough under hydrogen plasma treatment irrespective of the treatment time, indicating that the Fe surface is modified. For up to treatment time of $1 \mathrm{~min}$, the Fe surface is lumpy, and then it coheres over the treatment time span from 5 to 10 min. After treatment time of $20 \mathrm{~min}$, the surface condition of the Fe produces particles whose sizes decrease with increasing treatment time.

In general, when the catalyst was introduced in a hydrogen atmosphere, catalyst particle sizes increased with increasing of microwave power, catalyst thickness, or treatment time. Chen reported that the $\mathrm{Cr}$ surface becomes rough and forms particles whose sizes increase with increasing treatment time, when $\mathrm{Cr} / \mathrm{Si}$ (Cr thickness: $100 \mathrm{~nm}$ ) was treated by biased hydrogen plasma $(-150 \mathrm{~V})$ [12]. Wang et al. reported the formation of Ni nanoparticles by hydrogen plasma treatment of $\mathrm{Ni} / \mathrm{TiN} / \mathrm{Si}$ [13], and Choi et al. reported that $\mathrm{Ni}$ particles were formed by $\mathrm{NH}_{3}$ plasma treatment of $\mathrm{Ni} / \mathrm{Si}$ [14].

The formation of catalyst particles is different with previous studies because of the different of catalyst metal, catalyst thickness and microwave power with their condi- 


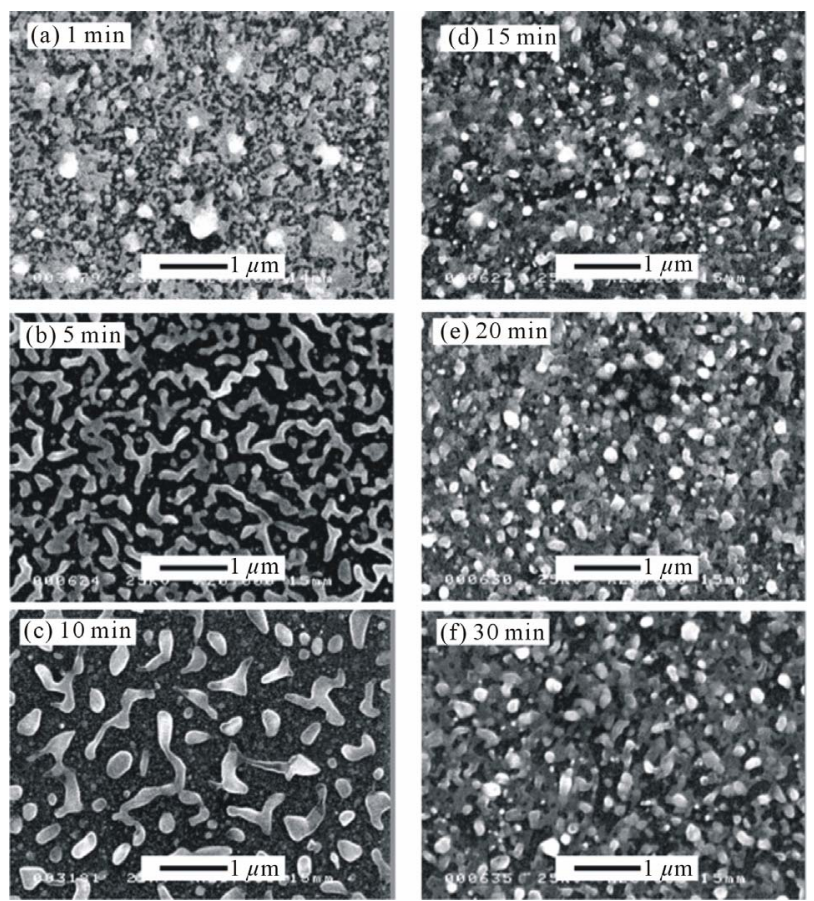

Figure 2. SEM image of $\mathrm{Fe} / \mathrm{Si}$ surface treated for various times by biased $\mathrm{H}_{2}$ plasma.

tions. When $\mathrm{Fe} / \mathrm{Si}$ was used, Fe was cohered over the treatment time span from 5 to $10 \mathrm{~min}$ because the melting point of $\mathrm{Fe}$ is lower than that of $\mathrm{Cr}$. The decrease in the size of the catalyst particles for plasma treatment times exceeding 10 min might be caused by etching with the hydrogen plasma.

\subsection{Plasma Decomposition of Methane over $\mathrm{Fe} / \mathrm{Si}$ Activated by Biased $\mathrm{H}_{2}$ Plasma}

In order to investigate the effect of catalyst on plasma decomposition of methane, $\mathrm{X}_{\mathrm{CH}_{4}}$ and hydrogen distribution were compared when the reaction was preceded under non-catalyst or $\mathrm{Fe} / \mathrm{Si}$ (without treatment).

Figure 3 shows the comparison of $\mathrm{X}_{\mathrm{CH}_{4}}$ and the comparison of the hydrogen distribution of output gases from $\mathrm{CH}_{4}$, when $\mathrm{Fe} / \mathrm{Si}$ was not used and $\mathrm{Fe} / \mathrm{Si}$ was used. In this case, $\mathrm{Fe} / \mathrm{Si}$ was not treated by biased hydrogen plasma. When $\mathrm{Fe} / \mathrm{Si}$ was used, $\mathrm{X}_{\mathrm{CH}_{4}}$ is slightly decreased from $86 \%$ to $83 \%$. The hydrogen distribution of output gases is almost the same value, and carbon was deposited on $\mathrm{Fe} / \mathrm{Si}$. Those results found that the both hydrogen and carbon can be obtained using $\mathrm{Fe} / \mathrm{Si}$.

In order to active catalyst for the production of hydrogen and deposited carbon, $\mathrm{Fe} / \mathrm{Si}$ was treated at various treatment times by biased hydrogen plasma.

Figure 4 shows the relationship between treatment time of biased hydrogen plasma and $\mathrm{X}_{\mathrm{CH}_{4}} \cdot \mathrm{X}_{\mathrm{CH}_{4}}$ is slightly decreased from $83 \%$ to $76 \%$ with an increase of treatment time.

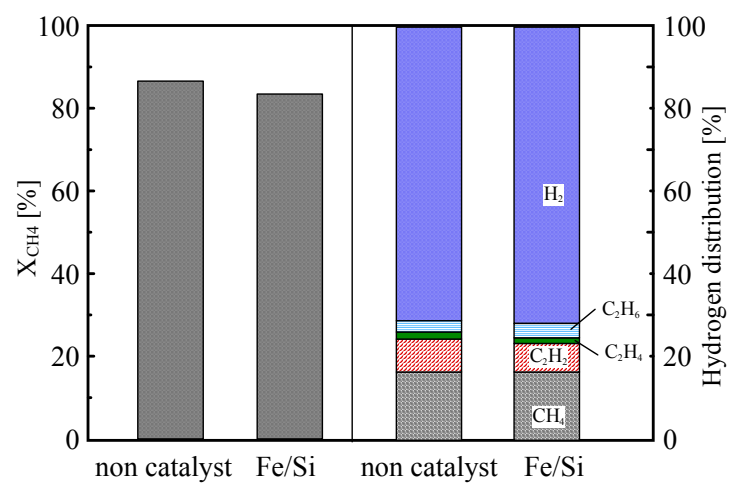

Figure 3. The comparison of methane conversion and hydrogen distribution when the reaction was proceeded under non-catalyst and $\mathrm{Fe} / \mathrm{Si}$ (without biased hydrogen plasma treatment).

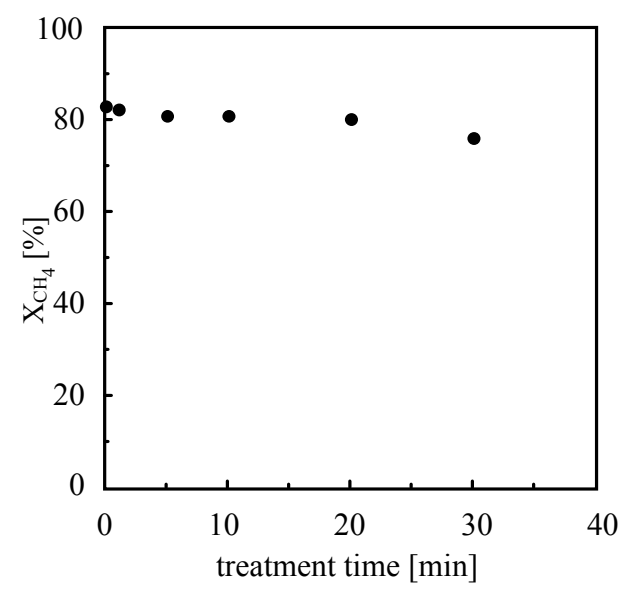

Figure 4. Effect of treatment time of biased hydrogen plasma on methane conversion.

This is probably due to the decrease of catalyst activetion. This factor might be the increase of $\mathrm{Fe}$ particle size and deposited carbon.

Figure 5 shows the relationship between treatment time and the hydrogen distribution of output gases from $\mathrm{CH}_{4}$. Hydrogen element of $\mathrm{CH}_{4}$ was mainly distributed to $\mathrm{H}_{2}$ irrespective of treatment time. However, $\mathrm{H}_{2}$ of hydrogen distribution was not increased with an increase of the treatment time of biased hydrogen plasma. This is due to the decrease of catalyst activation by carbon deposition. Hydrogen distribution of $\mathrm{C} 2$ hydrocarbon at treatment time of $1 \mathrm{~min}$ is larger than that at other treatment time. It is probably because reaction mechanism on catalyst is difference of other catalyst.

Figure 6 shows the relationship between treatment time and the amount of deposited carbon. The amount of deposited carbon decreases until treatment time of $5 \mathrm{~min}$.

Beyond treatment time of $10 \mathrm{~min}$, the amount of carbon deposited increases and attains a maximum value $\left(22.0 \mathrm{~g}_{\mathrm{c}} / \mathrm{g}_{\mathrm{cat}}\right)$ at treatment time of $20 \mathrm{~min}$.

Venugopal et al. also reported that the hydrogen yield 


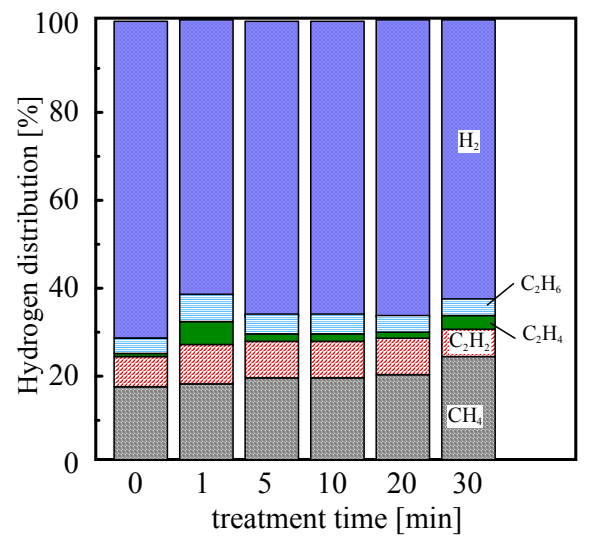

Figure 5. Effect of treatment time of biased hydrogen plasma on hydrogen distribution of output gases.

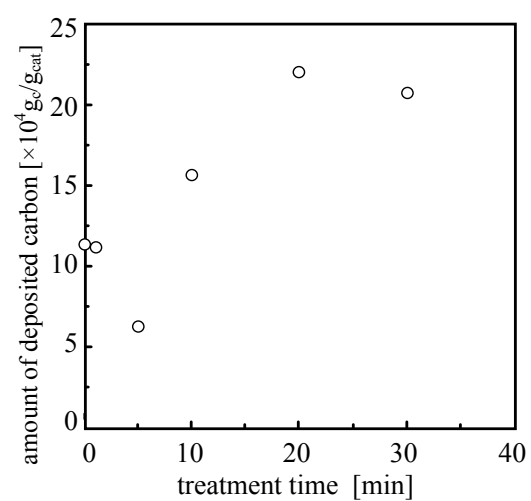

Figure 6. Effect of treatment time of biased $\mathrm{H}_{2}$ plasma on the amount of deposited carbon.

and carbon yield obtained from methane decomposition over $\mathrm{Ni} / \mathrm{SiO}_{2}$ indicated the maximum value at $\mathrm{Ni}$ particle size of $21 \mathrm{~nm}$ in the range of Ni particle size from 17 to $40 \mathrm{~nm}$ [4]. The decrease of the amount of deposited carbon at treatment time of $5 \mathrm{~min}$ is probably due to the decrease of the activated sites on catalyst by cohering Fe. The factor of the maximum value at treatment time of 20 min is due to the highest activated on $\mathrm{Fe} / \mathrm{Si}$ surface. It is well known that the methane conversion, the hydrogen yield and the amount of deposited carbon depended on catalyst particle size, and catalyst activation generally decreases by the increase of catalyst particle size. As showing Figure 2, the $\mathrm{Fe} / \mathrm{Si}$ surface changed with the different treatment time. The Fe has cohered at the treatment time of $5 \mathrm{~min}$, and the surface condition of the $\mathrm{Fe}$ produces particles in the range of treatment time from 10 min to $30 \mathrm{~min}$.

\subsection{SEM and TEM Image of Deposited Carbon}

Figure 7 shows the SEM images of the multi-walled CNTs (MWCNTs). When Fe/Si without hydrogen plasma treatment was used, the main deposited carbon forms particle. However, MWCNT growth occurs mainly after the treatment time of $1 \mathrm{~min}$.

Koyano et al. reported that the catalyst was more activated by the plasma treatment [15] and, as discussed above, the surface condition appears to be due to an increase in catalyst activation. The MWCNTs grow to various vertical heights, which is the same result as obtained in the previous studies that formed CNTs on the catalyst substance by microwave plasma treatment [16-19].

The heights of MWCNTs as a function of plasma treatment times are summarized in Table 1. The maximum height of the MWCNTs increases with increasing plasma treatment time, and reaches $30.7 \mathrm{~nm}$ at $10 \mathrm{~min}$. This trend is the same as that reported by Sato [19], who observed a maximum height of $11 \mathrm{~nm}$ for CNTs prepared on $\mathrm{Fe} / \mathrm{Si}$ after 10 min of plasma treatment. When using various thicknesses of cobalt as a catalyst, the CNT length decreases with increasing cobalt thickness [19]. Sato used $\mathrm{Fe} / \mathrm{Si}$ with 70-nm-thick Fe [19]. However here, we used $\mathrm{Fe} / \mathrm{Si}$ with 10 -nm-thick Fe. Therefore, the different MWCNT lengths might be attributed the different Fe thicknesses.

Figure 8 shows the typical TEM images of the MWCNTs, from which we measured the MWCNT diameters. The diameter reaches a maximum value of $22.5 \mathrm{~nm}$ at treatment time of 20 min and a minimum value of $9.8 \mathrm{~nm}$ at treatment time of $30 \mathrm{~min}$. It is well known that the MWCNT diameter is related to the particle size of the metal catalyst. We have also observed that MWCNT diameters increase with increasing metal catalyst particle
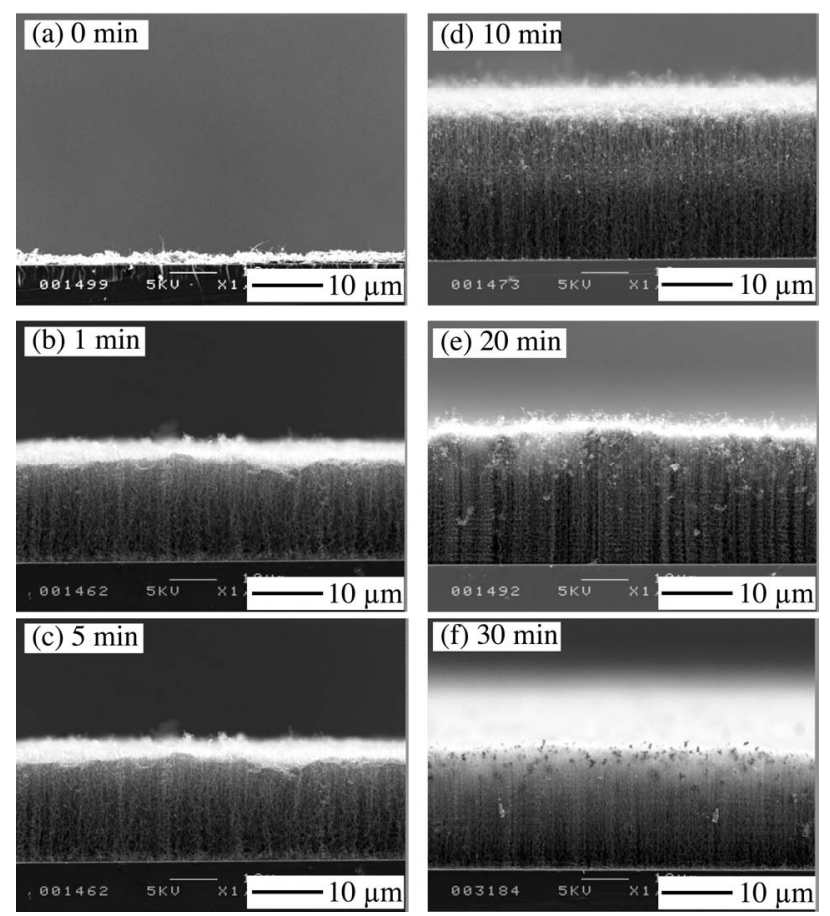

Figure 7. SEM images of carbon nanotubes obtained on the $\mathrm{Fe} / \mathrm{Si}$ treated for various treatment times by biased $\mathrm{H}_{2}$ plasma. 
Table 1. Summary of yield of deposited carbon and the characteristic of CNTs.

\begin{tabular}{|c|c|c|c|c|c|c|}
\hline Treatment time & Yield of deposited carbon & \multirow{2}{*}{ Shape } & \multirow{2}{*}{ Structure } & Length of CNT & Diameter of CNT & $I_{\mathrm{D}} / I_{\mathrm{G}}$ \\
\hline$[\mathrm{min}]$ & {$\left[\mathrm{g}_{\mathrm{c}} / \mathrm{g}_{\mathrm{cat}}\right]$} & & & {$[\mu \mathrm{m}]$} & {$[\mathrm{nm}]$} & {$[-]$} \\
\hline 0.0 & 2.6 & mainly particle & - & - & - & - \\
\hline 1.0 & 11.3 & fiborous & multi-walled & 15.4 & 15.4 & 0.71 \\
\hline 5.0 & 6.3 & fiborous & multi-walled & 21.7 & 12.6 & 0.68 \\
\hline 10.0 & 15.8 & fiborous & multi-walled & 30.7 & 22.5 & 0.56 \\
\hline 20.0 & 22.0 & fiborous & multi-walled & 28.5 & 15.3 & 0.52 \\
\hline 30.0 & 20.7 & fiborous & multi-walled & 24.6 & 9.8 & 0.72 \\
\hline
\end{tabular}

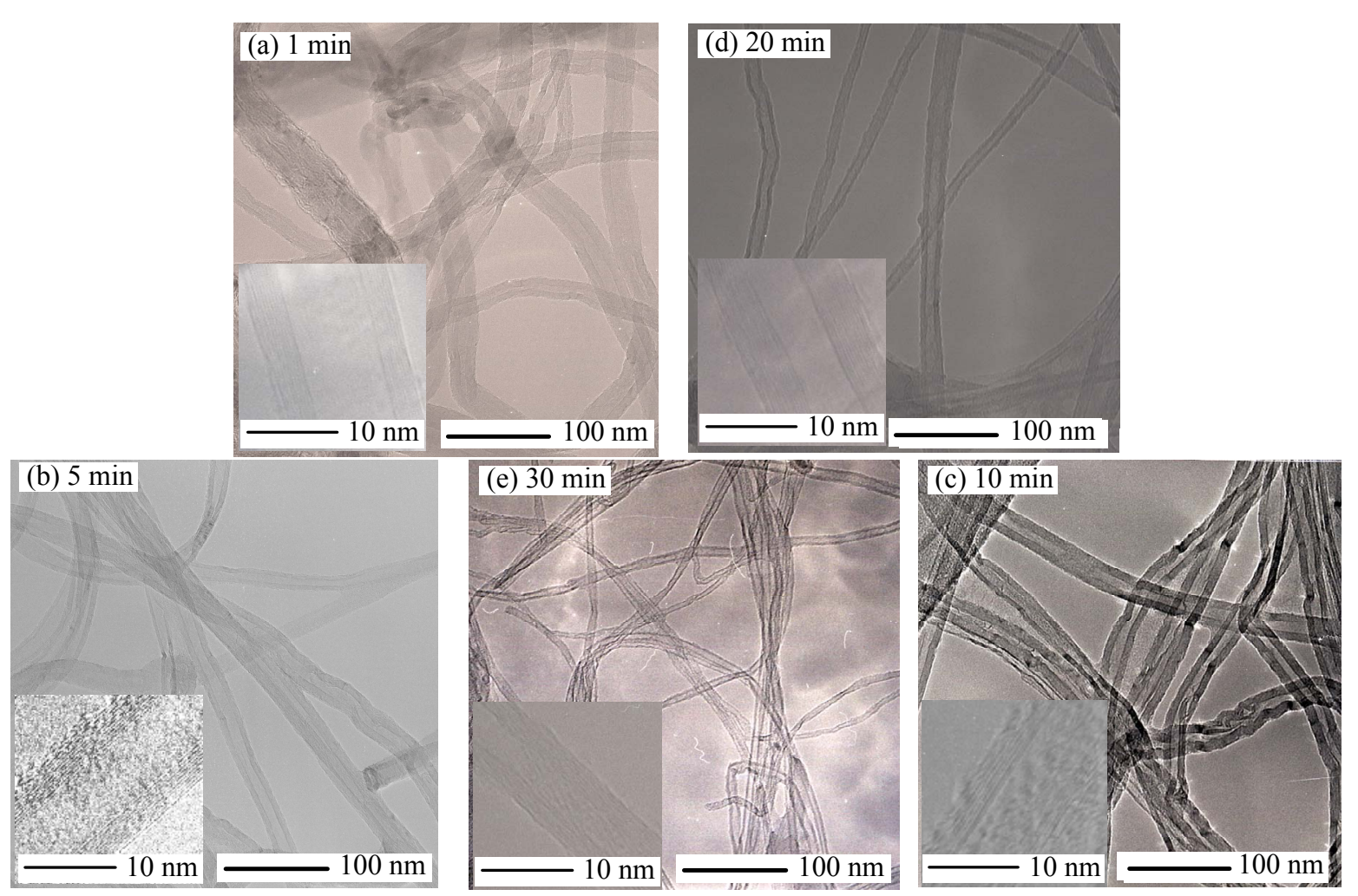

Figure 8. TEM images of carbon nanotubes obtained on the Fe/Si treated for various treatment times by biased $\mathrm{H}_{2}$ plasma.

size in the microwave plasma technique [20]. In that study, we measured the Fe catalyst particle size using atomic force microscopy and found that the Fe particle size shrinked from $127 \mathrm{~nm}$ after treatment time of $20 \mathrm{~min}$ to $95 \mathrm{~nm}$ after treatment time of $30 \mathrm{~min}$. Consequently, the different MWCNT diameters in the present study may be due to the change in size of the metal catalyst particle because of the varying treatment time.

The high-magnification TEM image shown in Figure 8 indicates that there are parallel graphite layers between the inner and outer walls of the MWCNTs regardless of plasma treatment time.

However, the number of graphite layers change with plasma treatment time, which suggests that the catalyst particles change as a function of plasma treatment time because it is known that the number of graphite layers depends on the condition of the catalyst, such as whether the catalyst is a particle and the catalyst surface roughness $[14,20]$.

\section{Conclusions}

Methane was decomposed by microwave plasma with catalyst, which Fe surface condition was activated by biased hydrogen plasma for various treatment times.

$\mathrm{X}_{\mathrm{CH}_{4}}$ was over $76 \%$ irrespective of the treatment time. The hydrogen distribution of output gas was mainly 
hydrogen (over 60\%) irrespective of the treatment time. It is hopeful to increase the hydrogen yield by the further improtant of reaction conditions, especially the property and volume of catalyst.

The amount of deposited carbon was $22 \mathrm{~g}_{\mathrm{c}} / \mathrm{g}_{\mathrm{cat}}$ at biased hydrogen treatment time of $10 \mathrm{~min}$. The deposited carbon was filamentous, and it grew vertically on $\mathrm{Fe}$ surface and was multi-walled carbon nanotubes. The diameter and graphite layer was difference by biased hydrogen treatment time.

\section{REFERENCES}

[1] J. R. Fincke, R. P. Snderson, T. A. Hyde and B. A. Detering, "Plasma Pyrolysis of Methane to Hydrogen and Carbon Black," Industrial and Engineering Chemistry Research, Vol. 41, No. 6, 2002, pp. 1425-1435. doi:10.1021/ie010722e

[2] J. L. Pinilla, I. Suelve, M. J. Lazaro, R. Moliner and J. M. Palacios, "Parametric Study of the Decomposition of Methane Using a $\mathrm{NiCu} / \mathrm{Al}_{2} \mathrm{O}_{3}$ Catalyst in a Fluidized Bed Reactor," International Journal of Hydrogen Energy, Vol. 35, No. 18, 2010, pp. 9801-9809. doi:10.1016/j.ijhydene.2009.10.008

[3] D. Li, J. Chen and Y. Li, "Evidence of Composition Deviation of Metal Particles of a Ni-Cu/ $\mathrm{Al}_{2} \mathrm{O}_{3}$ Catalyst during Methane Decomposition to Cox-Free Hydrogen," International Journal of Hydrogen Energy, Vol. 34, No. 1, 2009, pp. 299-307. doi:10.1016/j.ijhydene.2008.09.106

[4] A. Venugopal, S. Naveen Kumar, J. Ashok, D. H. Prasad, V. D. Kumari, K. B. S. Prasad and M. Subrahmanyam, "Hydrogen Production by Catalytic Decomposition of Methane over $\mathrm{Ni} / \mathrm{SiO}_{2}$," International Journal of Hydrogen Energy, Vol. 32, No. 12, 2007, pp. 1782-1788. doi:10.1016/i.ijhydene.2007.01.007

[5] Y. Echegoyen, I. Suelves, M. J. Lazaro, R. Moliner and J. M. Palacios, "Hydrogen Production by Thermocatalytic Decomposition of Methane over Ni-Al and Ni-Cu-Al Catalysts: Effect of Calcination Temperature," Journal of Power Sources, Vol. 169, No. 1, 2007, pp. 150-157. doi:10.1016/j.jpowsour.2007.01.058

[6] I. Suelves, M. J. Lazaro, R. Moliner, B. M. Corbella and J. M. Palacios, "Hydrogen Production by Thermo Catalytic Decomposition of Methane on Ni-Based Catalysts: Influence of Operation Conditions on Catalyst Deactivation and Carbon Characteristics," International Journal of Hydrogen Energy, Vol. 30, No. 15, 2005, pp. 1555-1567. doi:10.1016/j.ijhydene.2004.10.006

[7] M. A. Ermakova, D. Y. Ermakov and G. G. Kuvshinov, "Effective Catalysts for Direct Cracking of Methane to Produce Hydrogen and Filamentous Carbon Part I. Nickel catalysts," Applied Catalysisi A: General, Vol. 201, No. 1, 2000, pp. 61-70. doi:10.1016/S0926-860X(00)00433-6

[8] A. F. Cunha, J. J. M. Orfao and J. L. Figueiredo, "Methane Decomposition on Fe-Cu Raney-Type Catalysts," Fuel Processing Technology, Vol. 90, No. 10, 2009, pp. 1234-1240. doi:10.1016/j.fuproc.2009.06.004

[9] A. Konieczny, K. Mondal, T. Wiltowski and P. Dydo,
"Catalyst Development for Thermocatalytic Decomposition of Methane to Hydrogen. International Journal of Hydrogen,” Energy, Vol. 33, No. 1, 2008, pp. 264-272.

[10] N. Shah, D. Panjala and G. P. Huffman, "Hydrogen Production by Catalytic Decomposition of Methane," Energy \& Fuels, Vol. 15, No. 6, 2001, pp. 1528-1534. doi:10.1021/ef0101964

[11] K. Onoe, A. Fujie, T. Yamaguchi and Y. Hatano, "Selective Synthesis of Acetylene from Methane by Microwave Plasma Reaction," Fuel, Vol. 76, No. 3, 1997, pp. 281281. doi:10.1016/S0016-2361(96)00228-1

[12] C. F. Chen, C. L. Lin and C. M. Wang, "Field Emission Properties of Verticall Allgned Carbon Nanotubes Grown on Bias-Enhanced Hydrogen Plasma Pretratment $\mathrm{Cr}$ Film," Thin Solid Films, Vol. 444, No. 1-2, 2003, pp. 6469. doi:10.1016/S0040-6090(03)01022-8

[13] W. P. Wang, H. C. Wen, S. R. Jian, J. Y. Juang, Y. S. Lai, C. H. Tsai, W. F. Wu, K. T. Chen and C. P. Chou, "The Effects of Hydrogen Plasma Pretreatment on the Formation of Vertically Aligned Carbon Nanotubes," Applied Surface Science, Vol. 253, No. 23, 2007, pp. 9248-9253. doi:10.1016/j.apsusc.2007.05.060

[14] J. H. Choi, T. Y. Lee, S. H. Choi, J. H. Han, J. B. Yoo, C. Y. Park, T. Jung, S. G. Yu, W. Yi, I. T. Han and J. M. Kim, "Chontrol of Carbon Nanotubes Density through Ni Nanoparticle Formation Using the Thermal and $\mathrm{NH}_{3}$ Plasma Treatment," Diamond Related Materials, Vol. 12, No. 3-7, 2003, pp. 794-798.

[15] G. Koyano, H. Watanabe, T. Okuhara, M. Misono, A. Nishijima, N. Matsubayashi and M. Imamura, "Highly Activate Supported Cobalt Oxide Catalysts Prepared by Low Temperature Oxgen Plasma," Sekiyu Gakkaishi, Vol. 36, No. 5, 1993, pp. 402-405. doi:10.1627/jpi1958.36.402

[16] Y. C. Choi, Y. M. Shin, Y. H. Lee, B. S. Lee, G. S. Park, W. B. Choi, N. S. Lee and J. M. Kin, "Controlling the Diameter, Growth Rate, and Density of vertically Aligned Carbon Nanotubes Synthesized by Microwave PlasmaEnhanced Chemical Vapor Deposition," Applied Physics Letters, Vol. 76, No. 7, 2000, pp. 2367-2369. doi: $10.1063 / 1.126348$

[17] J. Y. Lee and B. S. Lee, "Nitrogen Induced Structure Control of Vertically Aligned Carbon Nanotubes Synthesized by Microwave Plasma Enhanced Chemical Vapor Deposition," Thin Solid Film, Vol. 418, No. 2, 2002, pp. 85-88. doi:10.1016/S0040-6090(02)00788-5

[18] M. Taniguchi, H. Nagao, M. Hiramatsu, Y. Ando and M. Hori, "Preparation of Dense Carbon Nanotube Film Using Microwave Plasma-Enhanceed Chemical Vapor Deposition," Diamond Related Materials, Vol. 14, No. 3-7, 2005, pp. 855-858.

[19] H. Sato, H. Takegawa and Y. Saito, "Veticall Aligned Carbon Nanotubes Grown by Plasma Enhanced Chemical Vapor Deposition," Journal of Vacuum Science and Technology B, Vol. 21, No. 6, 2003, pp. 2564-2568. doi:10.1116/1.1627332

[20] C. B. Bower, O. Zhou, W. Zhu, D. J. Werder and J. Sungho, "Nucleation and Growth of Carbon Nanotubes by Microwave Plasma Chemical Vapor Deposition," Applied Physics Letters, Vol. 77, No. 17, 2000, pp. 12767- 
12769. doi:10.1063/1.1319529

[21] K. Konno, K. Onoe and T. Yamaguchi, "Production of Carbon Nanotubes from Methane by Microwave Plas-
ma-Examination of Nickel Catalysis," Proceeding of 10th Asia Pacific Confederation of Chemical Engineering, Kitakyusyu, 17-21 October 2004, pp. 705-714. 